\title{
Investigating retroviral envelope proteome plasticity
}

\author{
Susanne Heider ${ }^{1}$, Feliks Kochan ${ }^{1}$, Sandra Kleinberger ${ }^{1}$, Eva Sperl ${ }^{1}$, Erik Reimhult ${ }^{2}$, Christoph Metzner ${ }^{1 *}$ \\ From Frontiers of Retrovirology: Complex retroviruses, retroelements and their hosts \\ Cambridge, UK. 16-18 September 2013
}

\begin{abstract}
Background
We have recently demonstrated that under highly artificial conditions, retroviral envelopes can acquire new proteins carrying a post-translationally added glycosylphosphatidylinositol (GPI) anchor [1,2]. Subsequently, we are interested to see if retroviral particles may acquire novel protein functions post-exit under physiological conditions either using GPI-anchored or, eventually, other protein species. Therefore we are trying to assess how mutable the envelope proteome is in response to external stimuli. New functionalities acquired in such processes, i.e. protection from the complement system, may prove beneficial for the virus, especially in zoonotic infections.
\end{abstract}

\section{Materials and methods}

Stably produced retro- and lenti-viral vectors based on HIV and MLV are used as viral model systems. Recombinantly produced GPI-anchored proteins carrying a 6xhis tag (monomeric green fluorescent protein - mGFP, the complement regulatory proteins CD55 and CD59 and Interleukin 2 - IL2) used as "insertion bait" molecules were purified via fast protein liquid chromatography (FPLC). Methods employed for analysis include immunoblotting, differential protein display and mass spectroscopy. Additionally, we are currently developing biophysical methodology for real-time label-free detection of changes at lipid bilayer surfaces, such as dual polarisation interferometry (DPI) or quartz crystal microbalances with dissipation monitoring (QCM-D), to follow insertion events.

\section{Results}

Levels comparable to physiological levels of proteins suffice for insertion of GPI anchored protein. When impure preparations (i.e. presence of high protein background) were used, association of GPI anchored proteins is still possible. When GPI anchored mGFP, CD59, or IL2 were added to lenti-viral vector particles, the respective functions could be conferred to the vector particles.

\section{Conclusions}

We have found that high protein backgrounds are permissive for insertion of low-abundance GPI anchored proteins and that protein functions are transferable with potential benefits for the virus (i.e. complement protection after transfer of CD55/CD59). Both findings support the hypothesis that retroviral particles may capture GPI anchored proteins from the surrounding media.

\section{Authors' details}

${ }^{1}$ Institute of Virology, University of Veterinary Medicine Vienna, Vienna, Austria. ${ }^{2}$ Institute of Biologically Inspired Materials, University of Natural Resources and Life Sciences Vienna, Vienna, Austria.

Published: 19 September 2013

\section{References}

1. Metzner C, Kochan F, Dangerfield JA: Fluorescence molecular painting of enveloped viruses. Mol Biotechnol 2013, 53:9-18.

2. Metzner C, Mostegl MM, Gunzburg WH, Salmons B, Dangerfield JA: Association of glycosylphosphatidylinositol-anchored protein with retroviral particles. Faseb J 2008, 22:2734-2739.

doi:10.1186/1742-4690-10-S1-P60

Cite this article as: Heider et al:: Investigating retroviral envelope proteome plasticity. Retrovirology 2013 10(Suppl 1):P60.

${ }^{1}$ Institute of Virology, University of Veterinary Medicine Vienna, Vienna,

Austria

Full list of author information is available at the end of the article

(c) 2013 Heider et al; licensee BioMed Central Ltd. This is an Open Access article distributed under the terms of the Creative Commons 